\title{
Measurement of Bubbles Properties to Generated Efficient Surface Flow
}

\author{
Hassan Abdulmouti ${ }^{1}$ \\ ${ }^{1}$ Department of Mechanical Engineering Division, Sharjah Men's College \\ Higher Colleges of Technology, Sharjah, UAE \\ habdulmouti@hct.ac.ae
}

\begin{abstract}
The objective of this paper is to evaluate the bubble properties and its motion, and to describe the characteristics of generating the surface flow in order to increase its efficiency (generate a strong, high, quick and wide surface flow over the bubble generation system). Moreover, to control the performance and the parameters of the surface flow such as: the thickness, the width and the velocity. Such flow depends on the gas flow rate, the bubble size (mean bubble diameter), void fraction, bubble velocity, the distance between the bubble generator and the free surface (the water height) and the temperature of the water. Laboratory experiments have been carried out in order to investigate the motion of bubbles, evaluate the bubble parameters, to discover their relationship, and improve the performance of the surface flow. The data was obtained by applying image processing of visualized images of the bubble flow structure for the different sections of the bubble regions. It has been confirmed that the temperature, bubble size and gas flow rate significantly affect the flow structure and bubble parameters.
\end{abstract}

Keywords: Multi-phase flow, Bubble plume, Bubble, Surface flow, Thermal and bubbly flow.

\section{Introduction}

Bubble columns are widely used in the petrochemical, pharmaceutical, biological fermentation, polymer polymerization, industrial wastewater treatment, environmental protection and metallurgical industries as multi-phase reactors and contactors because of their simple construction and ease of operation. The rising of a buoyancy-driving bubble in a liquid is one of the typical multi-fluid systems. A sound understanding of the fundamentals of the rising bubble is crucial in a variety of practical applications ranging from the rise of steam in boiler tubes to gas bubbles in oil wells. It is difficult to study the mechanism of the bubble behaviour through a purely theoretical method because of the strong nonlinearity accompanied by large bubble deformations [1-6]. The air bubble's velocity dependence has been determined experimentally by numerous investigators. When rising through an infinite stagnant liquid, the single bubble's terminal velocity is of fundamental importance in twophase flow [7-10], among others. The knowledge of bubble properties, including bubble velocity, bubble size, gas holdup, and specific interfacial area, is of importance for the proper design and operation of bubble columns [10-13]. An understanding of bubble-fluid interactions is important in a broad range of natural, engineering, and medical settings. Airsea gas transfer, bubble column reactors, oil/natural gas transport, boiling heat transfer, ship hydrodynamics, ink-jet printing and medical ultrasound imaging are just a few examples where the dynamics of bubbles play a role [14- 16].

This paper is concerned with the characteristics of bubble parameters that induce surface flow. These are the gas flow rate, the bubble size, bubble velocity, void fraction, and the internal two-phase flow structure of the bubble plume. Moreover, the temperature effect on the bubble parameter and its motion is evaluated. Image processing is applied after carrying out flow visualization for different sections of bubble regions in order to clarify the relationship between the bubble parameters, such as gas volume flow rate, mean bubble diameters, void fraction, water height in the tank (the height of the bubble plume which is equivalent to the distance between the bubble generator and the free surface), bubble velocity along the bubble plume, and the temperature of the liquid. The relationship between the bubble parameters is explained to improve the efficiency of the surface flow induced by bubble plume (generate a strong, high, quick and wide surface flow over the bubble generation system). Moreover, to control the performance and parameters of the surface flow such as: the thickness, the width and the velocity. The maximum speed of the surface flow induced by a bubble plume is governed by the flow structure in the initial region where the rising flow changes into a surface flow. The flow structure and bubble parameters are greatly affected by the gas flow rate, bubble size and liquid temperature. The surface flow is hence, expected to be an effective tool 
to support the function of an oil fence since it can generate a strong and wide surface flow over the bubble generation system, and it can damp the wave motion. This will help designing the real system of surface flow technique generated by the bubble plume to use it to control and collect surface floating substances in naval systems, lakes, seas, rivers, oceans especially the oil layer formed during large oil spill accidents. The surface flows generated by bubble plumes are considered key phenomena in various kinds of reactors, engineering processes and industrial processes handling a free surface.

\section{Experimental Apparatus, Method and Conditions}

The experimental apparatus for carrying out the experiments of the temperature effect on the bubble parameter measurements and its motion is constructed as shown in figure 1. The inner tank size is $750 \mathrm{~mm}$ in length, $500 \mathrm{~mm}$ in height, and $200 \mathrm{~mm}$ wide, and made of transparent acrylic resin. The experimental conditions are listed in Table 1. The bubble generator is installed at the centre of the bottom part of the tank. The bubble generator size is $300 \mathrm{~mm}$ in length, $20 \mathrm{~mm}$ in height, and $20 \mathrm{~mm}$ wide, made of transparent acrylic resin with 40 holes in the liner to avoid any over-lapping bubbles and to assure accurate two-dimensional measurements; each hole is $0.8 \mathrm{~mm}$ diameter and the distance between the holes is 7 $\mathrm{mm}$. The range of water temperature is selected to be from 20 to $50{ }^{\circ} \mathrm{C}$ in order to avoid high temperature of the bubble generator hence, to avoid any irregular performance and function0 of the bubble generator. A lighting setup (direct lighting method) with a black back sheet background and two LED lamps of $1000 \mathrm{~W}$ is used to clearly visualize and capture the images of the experiments for the measurements. The visualized flows are recorded by a digital video camera (Panasonic HC-MDH2) that captures $50 \mathrm{fps}$. The digital images are pre-processed through the video to JPEG converter image software and Adobe After Effects CS6 image processing software. In order to have more accurate measurement results, the tank height is extended to be $1200 \mathrm{~mm}$ and set of experiments are added for higher tank.

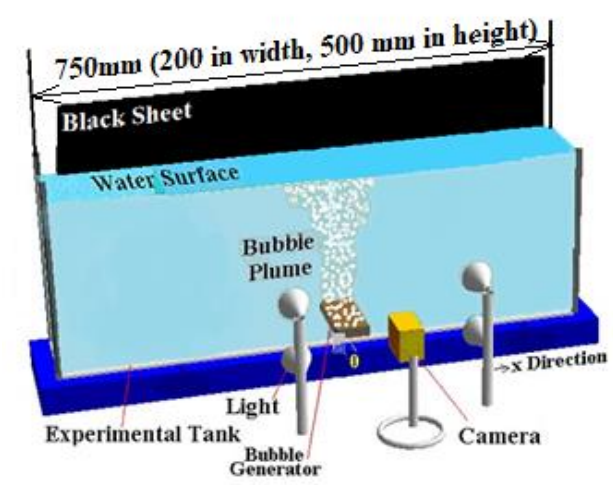

Fig. 1: Schematic diagram of experimental setup.

Table 1: Experimental and simulation conditions.

\begin{tabular}{|l|l|}
\hline Parameter & Value \\
\hline Density of water & $\rho=1000 \mathrm{~kg} / \mathrm{m}^{3}$ \\
\hline Kinematic viscosity of water & $\mathrm{v}=0.547 \times 10^{-6} \sim 10^{-6} \mathrm{~m}^{2} / \mathrm{s}$ \\
\hline Initial water height & $\mathrm{H}=0.1 \sim 1.2 \mathrm{~m}$ \\
\hline Atmospheric pressure & $101 \mathrm{kPa}$ \\
\hline Environment temperature & $22-25^{\circ} \mathrm{C}$ \\
\hline Temperature of Water & $20-50^{\circ} \mathrm{C}$ \\
\hline Density of gas (air) & $1.25 \mathrm{~kg} / \mathrm{m}^{3}$ \\
\hline Maximum gas flow rate & $\mathrm{Q}_{\mathrm{g}}=50 \times 10^{-5} \mathrm{~m}^{3} / \mathrm{s}$ \\
\hline
\end{tabular}


On the other hand, the void fraction $(\alpha)$ is calculated by using the equation $\left(\alpha=Q_{g} / A \times V_{b}\right)[1,4,17]$, where $A$ is the area of calculation in the injector region, (injector surface of the bubble generator). The bubble rising velocity $\mathrm{V}_{\mathrm{b}}$ is about 0.08 to $1.01 \mathrm{~m} / \mathrm{s}$. The bubble rise velocity is unsteady at the beginning (at the nozzle exit) and after a short period of time it reaches the terminal rise velocity. The measurement uncertainty for the rising bubble velocity is estimated to be about $2 \%$. The relative velocity between the bubbles and the liquid flow corresponds well to the terminal rising velocity of the bubble in a quiescent liquid. The measurement uncertainty for the void fraction is estimated to be about 2 to $3 \%$. This reflects the accuracy of the experimental results.

\section{Bubble Parameters Calculations}

The mean (average) bubble diameters and the bubble velocities are calculated for water heights of 100, 200, 300 and $400 \mathrm{~mm}$ respectively (referring to change the height of the free surface in the tank) and for three ranges of gas volume flow rates $\left[\mathrm{Qg}_{-1}\right.$ to $\left.\mathrm{Qg}_{-3}\right]$. The values of these calculation are achieved by using the time average of 250 consecutive frames in the image processing ( 5 seconds). The average bubble diameter, bubble velocity and the standard deviation are calculated by measuring more than 15000 bubbles in the local VTR images inside the bubble plume using image processing. These images are taken by recording local pictures of different regions. The experiments for measuring bubble size and velocity are conducted in three regions of the bubble plume: the first region is over the injector region of the bubble generator, the second is in the middle region of the bubble plume and the third is just under the free surface. Figure 2 shows samples of bubble images for different conditions of bubble generator including these regions. The first image to the life of the figure illustrates the bubbles for a gas flow rate of $\mathrm{Q}_{1}=1.5 \times 10^{-5} \mathrm{~m}^{3} / \mathrm{s}$ and water height of $\mathrm{H}=400 \mathrm{~mm}$ and temperature of $\mathrm{T}=30^{\circ} \mathrm{C}$. The middle image of the figure shows the bubbles for a gas flow rate of $\mathrm{Q}_{2}=28 \times 10^{-5} \mathrm{~m}^{3} / \mathrm{s}$ and water height of $\mathrm{H}=400 \mathrm{~mm}$ and temperature of $\mathrm{T}=30{ }^{\circ} \mathrm{C}$, and the third image to the right of the figure illustrates the bubbles for a gas flow rate of $\mathrm{Q}_{3}=50 \times 10^{-5} \mathrm{~m}^{3} / \mathrm{s}$ and water height of $\mathrm{H}=400 \mathrm{~mm}$ and temperature of $\mathrm{T}=30{ }^{\circ} \mathrm{C}$. The bubble diameter is defined by the equivalent bubble diameter using ellipsoidal approximations for the bubble shapes. The equivalent bubble diameter is estimated by the vertical and the horizontal lengths of each bubble of the image object, which are obtained by using the JPEG converter image software and Adobe After Effects CS6 image processing software after binarizing the images. The measurement uncertainty for the bubble diameter is estimated to be around $(0.01 \sim 0.015 \mathrm{~mm})$ of the averaged bubble diameter according to the pixel resolution. This reflects the accuracy of the experimental results. This reflects the accuracy of the experimental results since the number of frames and the time allocated for either the calculation and the measurement is rather long when compared to those by others $[2,5,10,17,20,21]$.

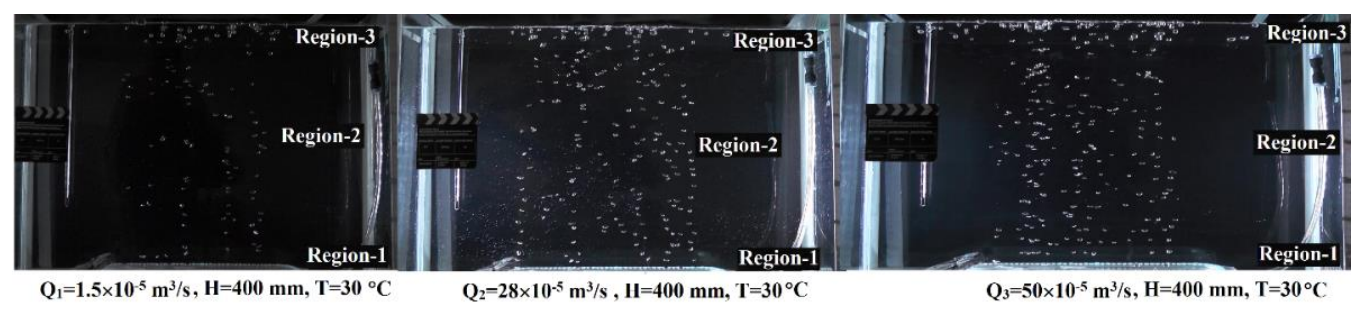

Fig. 2: Sample of bubble images.

Figure 3, 4, 5 and 6 show the relationship between bubble diameter and water height in the tank for water temperature of $\mathrm{t}=20,30,40$ and $50^{\circ} \mathrm{C}$ respectively. The data were collected for 3 gas volume flow rates $\left(\mathrm{Q}_{\mathrm{g} 1}=1.5 \times 10^{-5}, \mathrm{Q}_{\mathrm{g} 2}=28 \times 10^{-5}\right.$, $\left.\mathrm{Q}_{\mathrm{g} 3}=50 \times 10^{-5} \mathrm{~m}^{3} / \mathrm{s}\right)$. The bubble diameter is calculated for three regions or level of the height of the bubble plume: the first level is over the bubble generator (over the injector region of the bubble generator that is region L), the second is in the middle level height (the middle region which is Region $\mathrm{M}$ ) of the bubble plume and the third is just under the free surface which is region $\mathrm{H}$. 


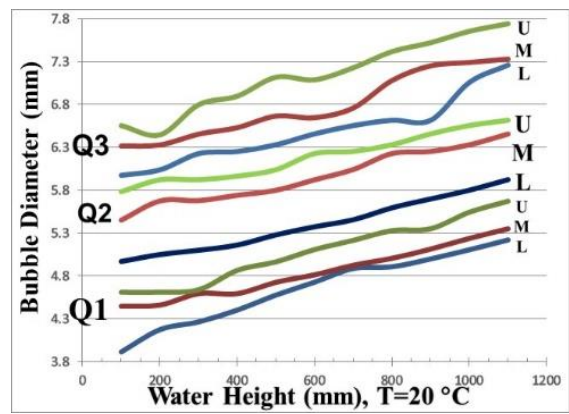

Fig. 3: A sample of the relationship between bubble diameter and water height for $\mathrm{t}=20^{\circ} \mathrm{C}$.

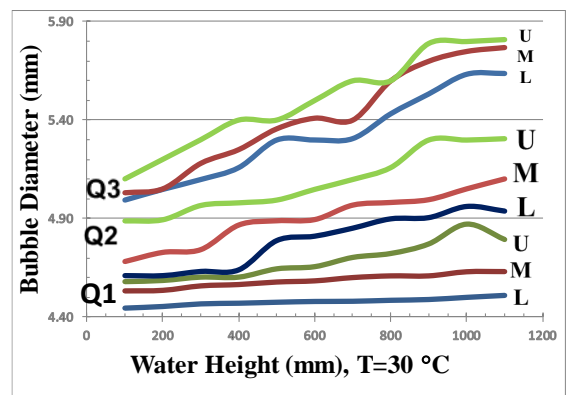

Fig. 4: A sample of the relationship between bubble diameter and water height for $\mathrm{t}=30^{\circ} \mathrm{C}$.

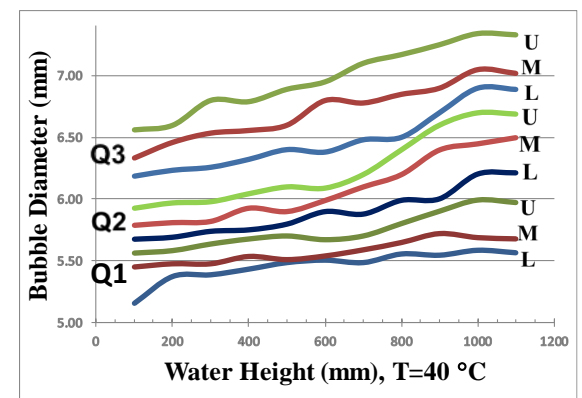

Fig. 5: A sample of the relationship between bubble diameter and water height for $\mathrm{t}=40{ }^{\circ} \mathrm{C}$.

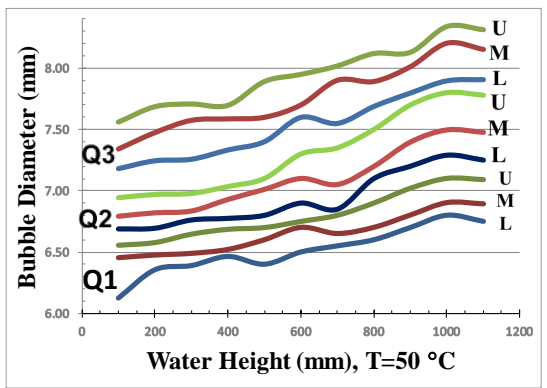

Fig. 6: A sample of the relationship between bubble diameter and water height for $\mathrm{t}=50^{\circ} \mathrm{C}$.

It is clear from these figures that the bubble size increases as the water height in the tank increases. These results are similar to the results obtained by our earlier paper $[16,18]$. Furthermore, the bubble size increases as the water temperature increases. It is clear from these figures that the bubble diameter increases about one $\mathrm{mm}$ when the water temperature increases by $10^{\circ} \mathrm{C}$. Figures $7,8,9$ and 10 illustrate samples of the relationship between the bubble velocity and water height in the 
tank for water temperature of $\mathrm{t}=20,30,40$ and $50{ }^{\circ} \mathrm{C}$ respectively. The data were collected for 3 gas volume flow rates $\left(\mathrm{Q}_{\mathrm{g} 1}=1.5 \times 10^{-5}, \mathrm{Q}_{\mathrm{g} 2}=28 \times 10^{-5}, \mathrm{Q}_{\mathrm{g} 3}=50 \times 10^{-5} \mathrm{~m}^{3} / \mathrm{s}\right)$. The bubble velocity is calculated for three regions or level of the height of the bubble plume L, M and $\mathrm{H}$. It is clear from these figures that the bubble velocity increases as the water height in the tank increases. Hence, the magnitude of bubble velocity increases along the bubble plume. It is also recognized that the bubble velocity magnitude in the middle region is almost 1.5 times of the bubble velocity magnitude over the bubble generator. Moreover, the bubble velocity magnitude under the free surface is almost twice the bubble velocity magnitude over the bubble generator. Furthermore, the bubble velocity increases as the water temperature increases. It is clear from these figures that by increasing the water temperature by $10^{\circ} \mathrm{C}$, the bubble velocity increases about 1.5 to 2 times. As temperature increases, viscosity and surface tension decrease because the raise in temperature speeds up the molecules and the movement makes the liquid move faster so the viscosity decreases, hence, the velocity of the bubble increases.

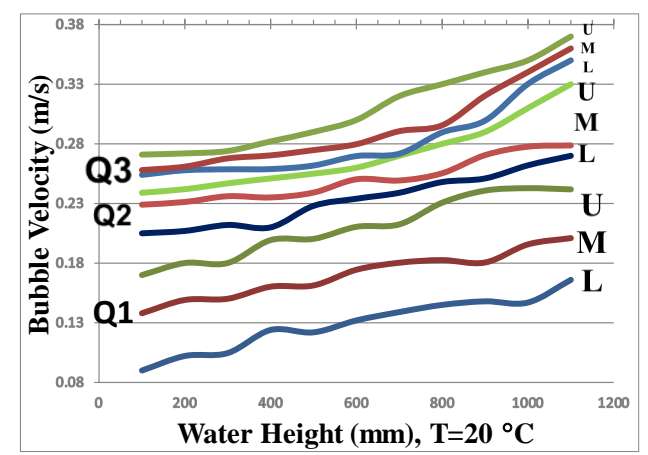

Fig. 7: A sample of the relationship between bubble velocity and water height for $\mathrm{t}=20^{\circ} \mathrm{C}$.

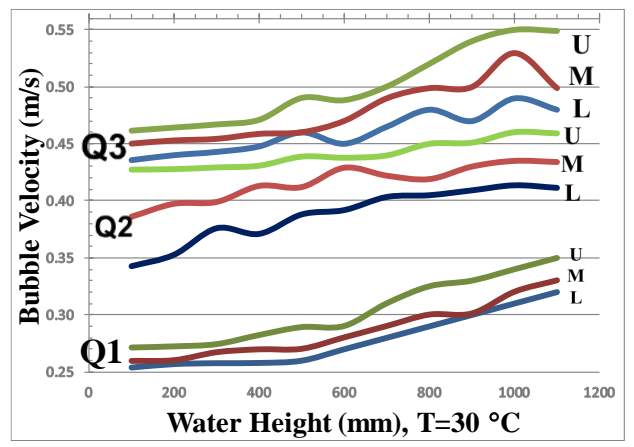

Fig. 8: A sample of the relationship between bubble velocity and water height for $\mathrm{t}=30^{\circ} \mathrm{C}$.

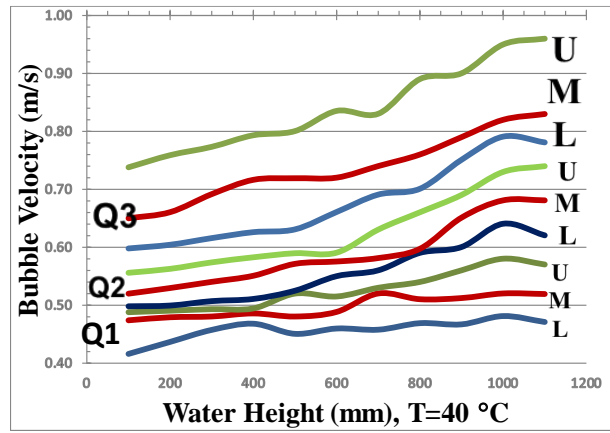

Fig. 9: A sample of the relationship between bubble velocity and water height for $\mathrm{t}=40{ }^{\circ} \mathrm{C}$. 


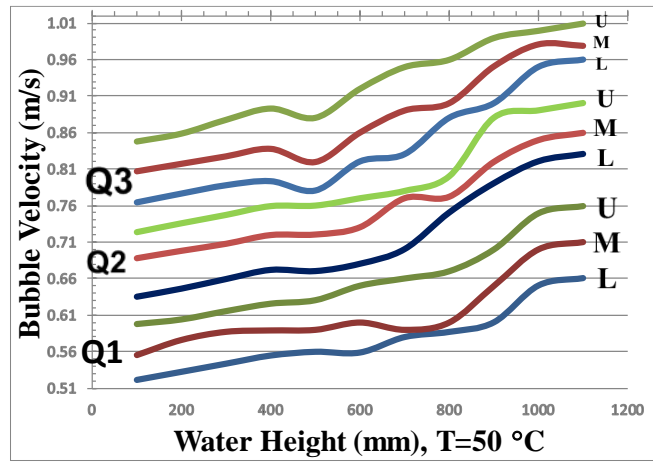

Fig. 10: A sample of the relationship between bubble velocity and water height for $\mathrm{t}=50^{\circ} \mathrm{C}$.

Figures 11, 12, 13 and 14 illustrate samples of the relationship between the void fraction $\alpha$ and water height in the tank for water temperature of $\mathrm{t}=20,30,40$ and $50{ }^{\circ} \mathrm{C}$ respectively. The data were collected for 3 gas volume flow rates $\left(\mathrm{Q}_{\mathrm{g} 1}=1.5 \times\right.$ $10^{-5}, \mathrm{Q}_{\mathrm{g} 2}=28 \times 10^{-5}, \mathrm{Q}_{\mathrm{g} 3}=50 \times 10^{-5} \mathrm{~m}^{3} / \mathrm{s}$ ). The void fraction is calculated for three regions or level of the height of the bubble plume L, M and $\mathrm{H}$. These figures confirm that as the water height increases the void fraction decreases. Furthermore, the void fraction decreases as the water temperature increases. It is clear from these figures that by increasing the water temperature by $10^{\circ} \mathrm{C}$, the void fraction decreases about 1 to 2 times.
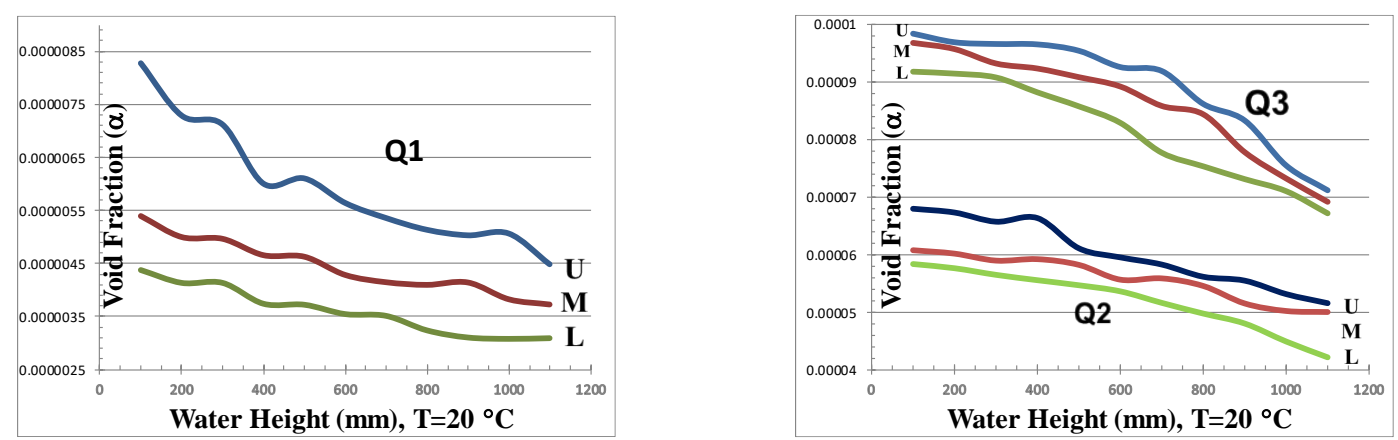

Fig. 11: A sample of the relationship between the void fraction $\alpha$ and water height for $t=20^{\circ} \mathrm{C}$, gas volume flow rate of $\mathrm{Q}_{1}, \mathrm{Q}_{2}$ and $\mathrm{Q}_{3}$.
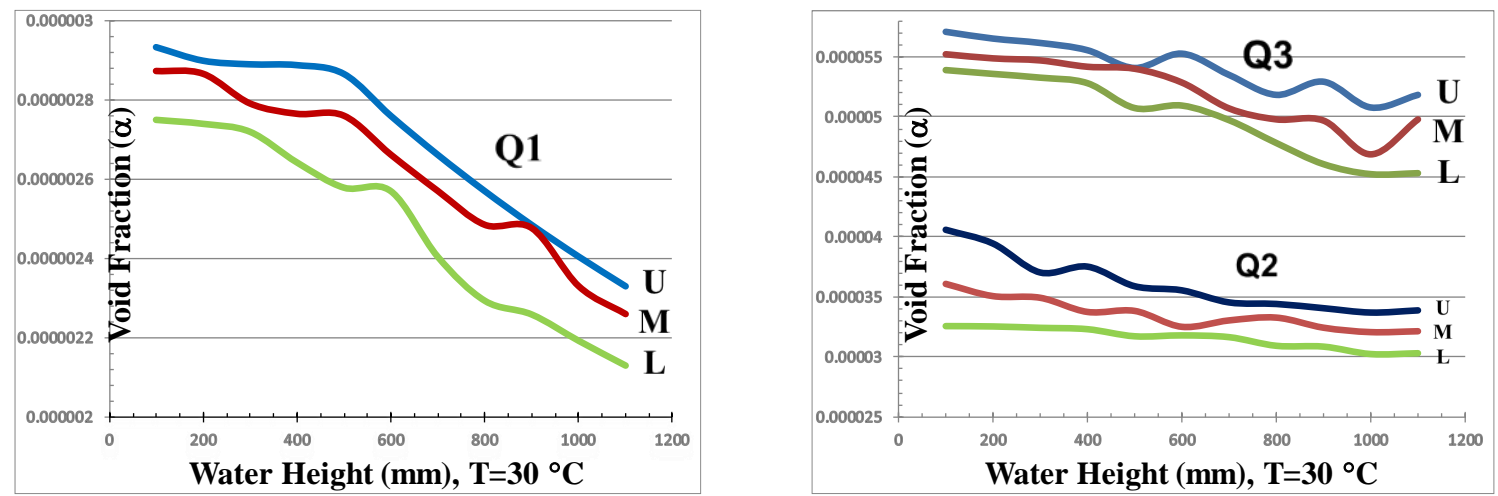

Fig. 12: A sample of the relationship between the void fraction $\alpha$ and water height for $\mathrm{t}=30^{\circ} \mathrm{C}$, gas volume flow rate of $\mathrm{Q}_{1}, \mathrm{Q}_{2}$ and $\mathrm{Q}_{3}$. 

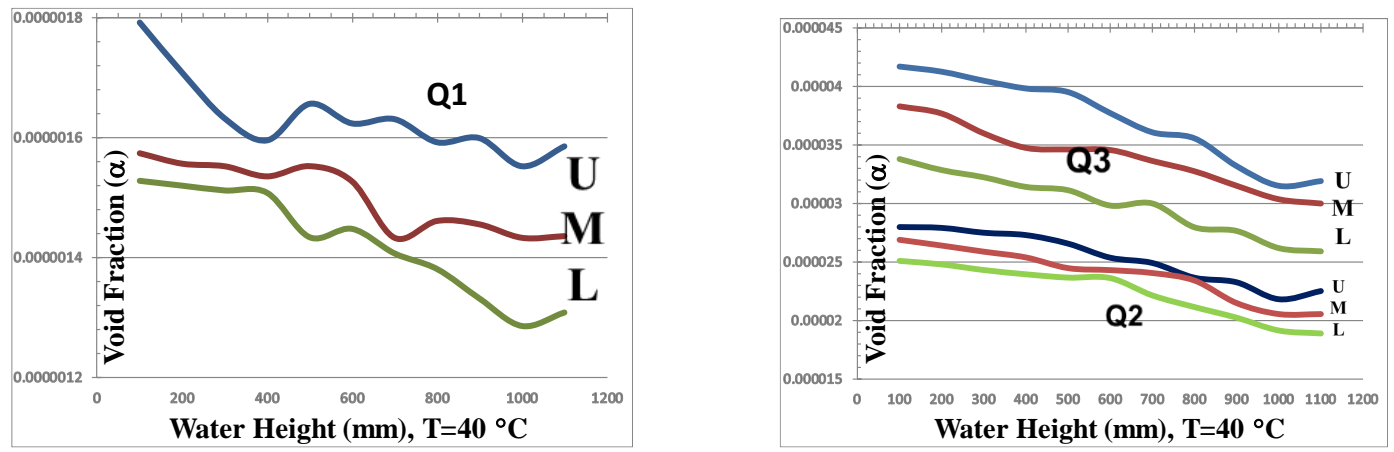

Fig. 14: A sample of the relationship between the void fraction $\alpha$ and water height for $t=40{ }^{\circ} \mathrm{C}$, gas volume flow rate of $\mathrm{Q}_{1}, \mathrm{Q}_{2}$ and $\mathrm{Q}_{3}$.
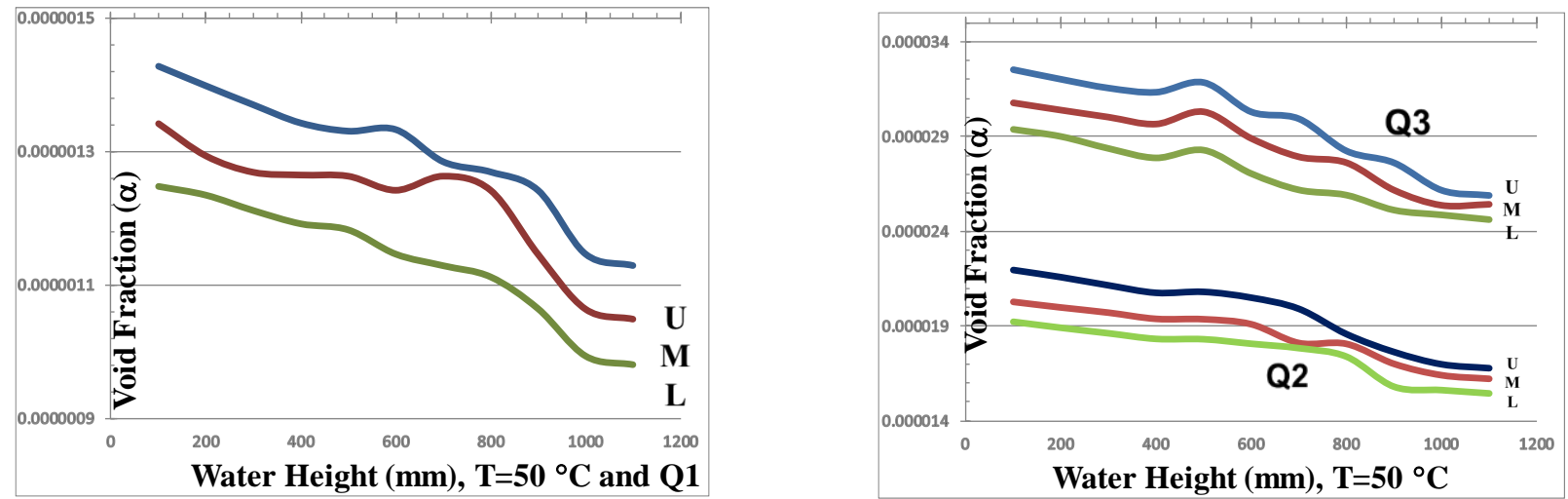

Fig. 15: A sample of the relationship between the void fraction $\alpha$ and water height for $t=50^{\circ} \mathrm{C}$, gas volume flow rate of $\mathrm{Q}_{1}, \mathrm{Q}_{2}$ and $\mathrm{Q}_{3}$.

Table 2 presents the relationship between the gas flow rate, water temperature and the width area of the bubble plume on the surface (the area which contains bubbles on the free surface "the width of the surface flow" in the horizontal direction), which is measured from video images. It is confirmed that this area increases when the gas flow rate increases. Moreover, this area increases when the water temperature increases. Hence, the higher the temperature, the stronger surface flow. It is clear from the table that by increasing the water temperature by $10^{\circ} \mathrm{C}$, the width of the surface flow increases about 2 to 4 mm.

As a result, the following properties are desired in order to generate efficient surface flow: higher temperature, bigger bubble size, higher water height, gas flow rate, hence higher velocity. 
Table 2: The relationship between the temperature and area width of the bubble plume on the free surface for 3 gas flow rates $\left(\mathrm{Q}_{\mathrm{g} 1}=1.5 \times 10^{-5}, \mathrm{Q}_{\mathrm{g} 2}=28 \times 10^{-5}, \mathrm{Qg}_{\mathrm{g}}=50 \times 10^{-5} \mathrm{~m}^{3} / \mathrm{s}\right)$.

\begin{tabular}{|l|l|l|}
\hline Gas volume flow rate $\mathbf{Q}_{\mathbf{g}}\left[\mathbf{m}^{\mathbf{3}} / \mathbf{s}\right]$ & $\begin{array}{l}\text { Water } \\
\text { temperature }\end{array}{ }^{\circ} \mathbf{C}$ & $\begin{array}{l}\text { Area width of surface flow } \\
(\mathbf{m m})\end{array}$ \\
\hline \multirow{2}{*}{$\mathbf{Q}_{\mathbf{g} 1}=\mathbf{1 . 5} \times \mathbf{1 0}^{-5}$} & 20 & 320 \\
\cline { 2 - 3 } & 30 & 322 \\
\cline { 2 - 3 } & 40 & 325 \\
\cline { 2 - 3 } & 50 & 329 \\
\hline \multirow{2}{*}{$\mathbf{Q}_{\mathbf{g} 2}=\mathbf{2 8} \times \mathbf{1 0}^{-5}$} & 20 & 345 \\
\cline { 2 - 3 } & 30 & 348 \\
\cline { 2 - 3 } & 40 & 350 \\
\cline { 2 - 3 } & 50 & 353 \\
\hline \multirow{2}{*}{$\mathbf{Q}_{\mathbf{g} 3}=\mathbf{5 0} \times \mathbf{1 0}^{-5}$} & 20 & 369 \\
\cline { 2 - 3 } & 30 & 372 \\
\hline & 40 & 376 \\
\cline { 2 - 3 } & 50 & \\
\hline
\end{tabular}

\section{Conclusion}

Flow visualization and image analysis of the bubble plume and bubble motion are carried out in order to improve the applicability of the bubble plume. The parameters of bubbles (mean bubble diameter, bubble velocity, gas flow rate, and the distance between the bubble generator and the free surface, which is equivalent to the water height in the tank) and the water temperatures are calculated, and their relation is demonstrated. The results of this paper resemble those results obtained by our earlier paper [19]. It was confirmed that the flow structure is greatly affected by the gas flow rate, bubble size and water temperature. The main results can be summarized as follows:

1) The bubble size increases as the water temperature increases. It is clear that the bubble diameter increases about one $\mathrm{mm}$ when the water temperature increases by $10^{\circ} \mathrm{C}$. The bubble size increases as the water height in the tank increase.

2) The bubble velocity increases as the water temperature increases. It is clear from that by increasing the water temperature by $10^{\circ} \mathrm{C}$, the bubble velocity increases about 1.5 to 2 times. Also, the bubble velocity increases as the water height in the tank increases, and the magnitude of bubble velocity increases along the bubble plume. Moreover, it is also recognized that the bubble velocity magnitude in the middle region is almost 1.5 times the bubble velocity magnitude over the bubble generator. Moreover, the bubble velocity magnitude under the free surface is almost twice the bubble velocity magnitude over the bubble generator.

3) The void fraction decreases as the water height increases. Furthermore, the void fraction decreases as the water temperature increases. By increasing the water temperature by $10^{\circ} \mathrm{C}$, the void fraction decreases about 1 to 2 times.

4) The width area of the bubble plume on the surface (the area which contains bubbles on the free surface "the width of the surface flow" in the horizontal direction) increases when the water temperature increases. Hence, the higher the temperature, the stronger surface flow. Moreover, this area increases approximately proportional to the gas flow rate.

5) The following properties are desired in order to generate efficient surface flow: higher temperature, bigger bubble size, higher water height, gas flow rate, hence higher velocity.

\section{Acknowledgment}

This paper was funded by the Internal Grant No: Seed-605 by The Higher Colleges of Technology.

\section{References}

[1] Gross R. W. and Kuhlman J. M, "Three-Component Velocity Measurements in a Turbulent Recarculating Bubble-Driven Liquid Flow," Int. J. Multiphase Flow, vol. 18, pp. 413-421, 1992. 
[2] Hara, S., Ikai, M., Namie, S, "Fundamental Study on an Air Bubble Type of Oil Boom.” Trans. Ship-Making Society of Kansai-Japan, vol. 194, 1984.

[3] Hassan, Abdulmouti, "Bubbly Two-Phase Flow: Part I- Characteristics, Structures, Behaviors and Flow Patterns" American Journal of Fluid Dynamics, Scientific and Academic Publishing, vol. 4, no. 4, pp. 194-240, December, 2014a.

[4] Hassan, Abdulmouti, "Experimental Measurements of Bubble Convection Models in Two-phase Stratified Liquids," Experimental Thermal and Fluid Science, vol. 83C, pp. 69-77, May 2017.

[5] Murai Yuichi, Ohno Yasushi, Abdulmouti Hassan, Yamamoto Fujio, "Flow in the Vicinity of Free Surface Induced by a Bubble Plume," JSME, vol. 67, no. 657 B, 2001.

[6] Wang Han, Zhang Zhen-Yu, Yang Yong-Ming, and Zhang Hui-Sheng, "Surface tension effects on the behavior of a rising bubble driven by buoyancy force," Chin. Phys. B., vol. 19, no. 2, 2010.

[7] Mário A. R. Talaia, "Terminal Velocity of a Bubble Rise in a Liquid Column," World Academy of Science, Engineering and Technology, vol. 28, 2007.

[8] G. P. Celata, M. Cumo, F. D'Annibale and A. Tomiyama, "Terminal bubble rising velocity in one-component systems," in Proc. of $39^{\text {th }}$ European Two-Phase Flow Group Meeting, CDROM, paper F-3, Aveiro, 2001.

[9] A. Tomiyama, "Grag, lift and virtual mass forces acting on a single bubble," In Proc. of the 3rd International Symposium on Two-Phase Flow Modelling and Experimentation, Edizioni ETS, Pisa, Italy, 2004.

[10] Matsumoto, Y., Murai, Y, "Numerical Simulation of Bubble Plume in a Tank with Free Surface." Trans. Jpn. Soc. Mech. Eng., vol. 61, no. 588 B, pp. 54-61, 1995.

[11] Matsumoto Y. and Prosperetti A, edit., Proc. ISAC'97 High Performance Computing on Multi-Phase Flows, 1997.

[12] Jager B., Espinoza R, “Advances in low temperature Fisher-Tropsch synthesis,” Catalysis Today, vol. 23, no. 1, pp. 17$28,1995$.

[13] Davis B. H., "Overview of reactors for liquid phase Fischer-Tropsch synthesis." Catalysis Today, vol. 71, no. 3-4, pp. 249-300, 2002.

[14] Junli Xue, "Bubble Velocity, Size and Interfacial Area Measurements in Bubble Columns," Washington University, Saint Louis, Missouri, December 2004.

[15] J. Magnaudet and I. Eames, "The motion of High-Reynolds-number bubbles in inhomogeneous flows," Ann. Rev. Fluid Mech., vol. 32, no. 659, 2000.

[16] Hassan, Abdulmouti., "The Measurements of Bubble Plume Structure Parameter," International Journal of Fluid Mechanics Research, vol. 44, no. 3, pp. 1-19, 2017.

[17] Murai Yuichi, Ido Takehiro, Ishikawa Masa-aki Yamamoto Fujio, "Development of the Post-Processing Method for PIV Measurement Result Using Computational Fluid Dynamics Procedure," Transaction of the Japan Society of Mechanical Engineers, vol. 64B-626, pp.109-116, 1998.

[18] Hassan Abdulmouti, "Measurements of Thermal Effect on Bubble Parameter," in Proceedings of the 3rd Thermal and Fluids Engineering Conference (TFEC), Fort Lauderdale, FL, USA, March 2018.

[19] Hassan Abdulmouti. Particle Imaging Velocimetry (PIV) Technique: Principles, the typically used methods, classification and applications. Scholar's Press, 2013.

[20] Isao K., Akimi, S., Besnard, D. C., "Prediction of Turbulence Suppression and Turbulence Modeling in Bubbly Two-Phase Flow," Nuclear Engineering and Design, vol. 141, pp. 145-158, 1993.

[21] Hassan, Abdulmouti, "2D- numerical simulation of surface flow velocity and internal flow structure generated by bubbles," Multiphase Science and Technology, vol. 28, no. 2, pp. 153-171, 2016. 